\title{
Direct Strain Distribution and Finite-Element-Analysis Simulation of the Bonding Interface of Bamboo Laminated Lumber with Ultrasound-Treated Bamboo Strips
}

\author{
Mingjie Guan a,b,c,* and Zhiwei Huang ${ }^{\text {a }}$ \\ An ultrasonic cavitation treatment was used to increase the permeability \\ of phenol formaldehyde resin adhesive on the surface of bamboo strips, \\ and two-ply laminated bamboo lumber was manufactured. The strain \\ distribution along the bamboo interface under stretching conditions was \\ investigated using the digital image correlation technique. The effect of the \\ ultrasonic treatment on the bamboo strips in terms of the shear strain of \\ the laminated bamboo lumber was investigated, and a finite-element \\ analysis for the bonding interface was carried out to evaluate whether the \\ deformation measurement could predict the mechanical behavior \\ differences of the laminated bamboo lumber. The digital image correlation \\ and shear strength results show that the strain was lower in the bamboo \\ bonding interface after ultrasonic treatment and the shear strength was \\ enhanced due to the increased adhesive penetration. The digital image \\ correlation measurement and finite-element analysis simulation both \\ showed that stress was more concentrated, and the strain value and strain \\ zone width was higher in the carbonized bamboo bonding interface than \\ in the bleached bamboo bonding interface. The finite-element analysis \\ results appeared to be in agreement with the digital image correlation test \\ results.
}

DOI: 10.15376/biores.17.1.890-907

Keywords: Ultrasonic treatment; Bamboo bonding interface; Digital image correlation; Finite-element analysis

Contact information: a: College of Materials Science and Engineering, Nanjing Forestry University, Nanjing, Jiangsu 210037 China; b: Bamboo Engineering and Technology Research Center of SFA, Nanjing Forestry University, Nanjing, Jiangsu 210037 China; c: Co-Innovation Center of Efficient Processing and Utilization of Forest Resources, Nanjing Forestry University Nanjing, Jiangsu 210037 China; *Corresponding author: mingjieguan@126.com

\section{INTRODUCTION}

Bamboo is a renewable natural green construction and building material that has the advantages of being environmentally friendly, sustainable, and has the capability to be recycled or reused. Bamboo-based composites, e.g., laminated bamboo lumber, bamboo scrimber, plybamboo, bamboo glulam, etc., can effectively alleviate the contradiction between the supply and demand of renewable materials in civil construction and the building industry (Li et al. 2013, 2015; Li et al., 2016; Xiao et al. 2017; Takeuchi et al. 2018; Chow et al. 2019; Li et al. 2019). Recently, laminated bamboo lumber has attracted increasing attention because of its excellent strength performance as a building material. Previous research has been primarily focused on the effect of the orientation direction on 
the mechanical properties and the effect of processing on the static bending properties and structural properties, physical-mechanical, and bonding performance, etc. (Xu et al. 2004; Correal and Ramirez 2010; Darzi et al. 2018; Bakar et al. 2019; Li et al. 2019; Rusch et al. 2019). Laminated bamboo lumber is bonded with adhesives, e.g., phenolic resin, so bond line and bonding interface characterization is important to ensure bonding performance (Correal and Ramirez 2010; Guan et al. 2014; Guan et al. 2016). It is necessary to improve adhesive penetration into the bamboo matrix. However, bamboo has a dense surface and an intrinsic lack of transverse tissue, e.g., wood rays (Liese 1998). Horizontal transmission only relies on pits in the cell walls, which may result in the shallow penetration of the adhesive into the bamboo and lead to unsatisfactory bonding performance (Ma 2009; Guan et al. 2014, 2016). Research has shown that micro-jets generated from ultrasonic cavitation may cause shock and a shear effect on the surface cells of bamboo strips. An ultrasonic treatment can enhance the permeability of the adhesive, relying on deeper and wider pits, and can, accordingly, increase the shear strength of laminated bamboo lumber (Guan et al. 2013).

It is known that the properties of bamboo engineered materials depends not only on the bamboo matrix itself but also on the properties of the bonding interface generated by mutual contacts with adhesives. The interface between the adhesive and bamboo plays a vital role in ensuring the performance of bamboo-based composite structure materials and their application (Guan et al. 2016). The strain distribution in the interface of wood composite materials influences the stress transmission and dispersion, which may influence the macro-performance of wood-based composites in terms of dimensional stability, durability, and shear strength (Serrano and Enquist 2005; Jeong et al. 2006; Gindl and Muller 2016). However, it is difficult to directly measure strain distribution in interfaces due to the thin character of the bond line, so contact-free measurement is usually used. Today, measurement of the bonding interface strain distribution of wood-based composites, e.g., plywood, wood adhesive bond line, wood block, and wood/adhesive interphase, is conducted by digital image correlation (DIC) (Serrano and Enquist 2005; Jeong et al. 2016; Guan et al. 2014; Gindl and Muller 2016). Relatively speaking, research on bamboo/based composites has employed DIC less often compared to wood-based composite research. Numerical simulation based on the finite element method has been frequently employed in strain simulations, for study of the bonding interface of wood particleboard, flooring, middle density fiberboard, timber, etc., or laminated Guadua bamboo lumber (Grigsby and Thumm 2004; Blanchet et al. 2005; Konnerth et al. 2006; Wong et al. 2003; He et al. 2012; Sebera et al. 2015; Takeuchi et al. 2018). However, previous research on bamboo or wood composites has primarily focused on macro-strain performance based on the assumption that the bonding quality is good, and the bond line adhesion has not changed. The effect of the bond line on the strain transmission is neglected, because its thickness is too thin to be considered in volume. However, the strain distribution of the bonding interface of laminated bamboo lumber made from ultrasoundtreated bamboo strips is still unknown.

In this study, bamboo strips were treated via ultrasonic cavitation, and two-ply laminated bamboo lumber was made with a phenol-formaldehyde resin adhesive. The micro-scale strain distribution of the bonding interface was tested under tensile load conditions via DIC to understand the bamboo adhesion mechanism before and after the ultrasonic treatment. The effects of the ultrasonic treatment on the bonding shear strength of the laminated bamboo lumber were discussed. Finite-element analysis (FEA) simulation results were also presented for comparison with the experimental test result, so as to further 
understand or characterize the stress transmission function of the bonding interface and the bamboo bonding mechanism.

\section{EXPERIMENTAL}

\section{Ultrasonic Treatment of the Bamboo Strips}

Bleached and carbonized Moso bamboo (Phyllostachys pubescens) strips (4 years old) were obtained from the Zhejiang Bamboo Factory (Zhejiang, China), each measuring $150 \mathrm{~mm} \times 20 \mathrm{~mm} \times 5 \mathrm{~mm}$. The strips were treated under water in an ultrasonic cell crushing machine. The ultrasonic treatment process for the bleached bamboo strips was carried out under the following conditions: a temperature of $60{ }^{\circ} \mathrm{C}$, a treatment time of $60 \mathrm{~min}$, and a power of $1200 \mathrm{~W}$. The ultrasonic treatment for the carbonized bamboo strips was carried out under the following conditions: a temperature of $60{ }^{\circ} \mathrm{C}$, a treatment time of $90 \mathrm{~min}$, and a power of $1400 \mathrm{~W}$. The bamboo strips were then dried under air-drying conditions and conditioned in a standard chamber (a temperature of $20^{\circ} \mathrm{C}$ and a relative humidity of $65 \%$ ) until a constant weight was reached.

\section{Parameters Testing of the Bamboo Strips for the Finite-element Analysis (FEA) Evaluation}

In order to conduct the FEA evaluation of the laminated bamboo lumber, the basic parameters of the bamboo strips before and after ultrasonic treatment were tested according to GB/T standard 15780 (1995). The longitudinal, radial, and tangential directions of bamboo were marked as $\mathrm{L}, \mathrm{R}$, and $\mathrm{T}$, respectively. The parameters of the bamboo strips used for the FEA simulation included the elastic modulus in three directions $\left(E_{L}, E_{R}\right.$, and $\left.\mathrm{E}_{\mathrm{T}}\right)$, Poisson's ratio in three directions $\left(\mu_{\mathrm{LR}}, \mu_{\mathrm{LT}}\right.$, and $\left.\mu_{\mathrm{RT}}\right)$, and the shear modulus of bamboo in three directions $\left(G_{\mathrm{LR}}, G_{\mathrm{LT}}\right.$, and $\left.G_{\mathrm{RT}}\right)$. These parameters were tested via tensile and calculated via DIC with 6 dog bone tensile samples using the size described in GB/T standard 15780 (1995). The test conditions of the DIC are shown in the following section (DIC measurement) with the same painted surface and 3D-camera system, loading steps, and calculation method.

\section{Preparation of the Two-Ply Laminated Bamboo Lumber}

The two-ply bleached and carbonized bamboo strips were laminated parallel to each other before and after ultrasonic treatment, and the assembly pattern was inner (the region close to the inner part of bamboo) to inner, i.e., low-density face to low-density face, as shown in Fig. 1. 


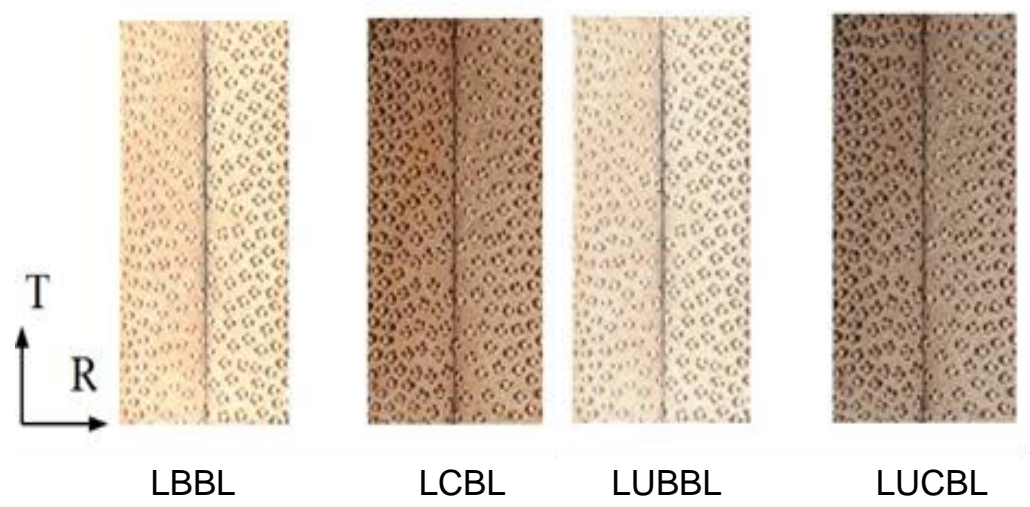

Fig. 1. Assembled patterns of the laminated bamboo lumber, i.e., inner to inner face: laminated bleached bamboo lumber (LBBL); laminated carbonized bamboo lumber (LCBL); laminated ultrasonically bleached bamboo lumber (LUBL); and laminated ultrasonically carbonized bamboo lumber (LUCBL)

The phenol formaldehyde (PF) adhesive was self-made and used at a solid content of $50 \%$. The specimens were all cured for $15 \mathrm{~min}$ in a Platen Vulcanizing Press at $1.2 \mathrm{MPa}$ and an ambient temperature of $140{ }^{\circ} \mathrm{C}$; the adhesive consumption was $140 \mathrm{~g} \cdot \mathrm{m}^{-2}$. After the curing process, the specimens were conditioned in a standard chamber (a temperature of $20{ }^{\circ} \mathrm{C}$ and a relative humidity of $65 \%$ until a constant weight was attained.

\section{Characterization of the Bonding Interface and Bondline Thickness Calculation}

A $30 \mu \mathrm{m} \times 3 \mathrm{~mm} \times 3 \mathrm{~mm}$ cross-section was taken from the bleached and carbonized laminated bamboo lumber samples upon ultrasonic treatment and the creation of a control group. Each specimen was softened by soaking in water at room temperature for $7 \mathrm{~d}$. The cross-sections were then cut and dehydrated with graded ethanol in gradient concentrations of $30 \%, 60 \%$, 95\%, and 100\%. After desiccation, fixing, and gold spraying (E-1010, Hitachi Ion Sputter, Jeol, Japan), the cross-sections were observed via scanning electron microscopy (SEM) (Quanta 200, FEI, Hillsboro, OR) at $20 \mathrm{kV}$ to evaluate the microstructure of the bonding interface and the adhesive bond line in the bamboo matrix. The thickness of the bond line was calculated according to Eq. 1,

$$
\mathrm{AT}={ }^{A} / x_{i}
$$

where AT is the average value of the bond line thickness, $\mu \mathrm{m} ; A_{i}$ is the objective area of the bonding interface (including the bond line), $\mu \mathrm{m}^{2}$; and $x_{i}$ is the objective length of the bonding interface, $\mu \mathrm{m}$;. Five replicates were conducted for one specimen and calculated 30 times at different distances along the length of the bond line in one image.

\section{Digital Image Correlation (DIC) Measurement}

The shear strength specimens were processed experimentally with the following specifications: a $150 \mathrm{~mm}$ length, a $20 \mathrm{~mm}$ width, and a $10 \mathrm{~mm}$ thickness, with a shear strength test rabbet of $2.5 \mathrm{~mm}$ on both sides, which was in accordance with DIN EN standard 302-1 (2004) (Fig. 2). 


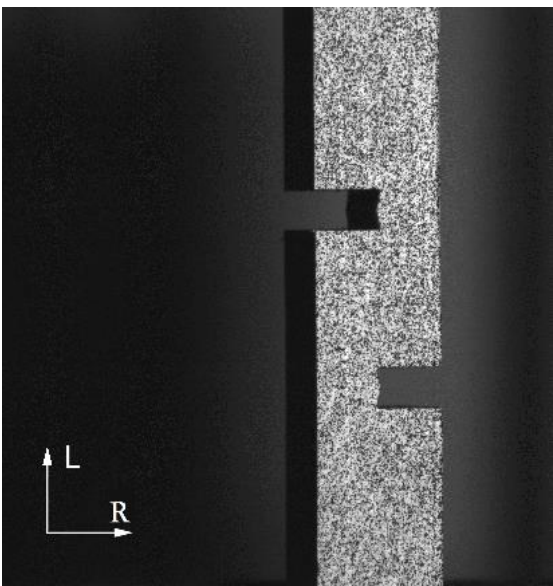

(a)

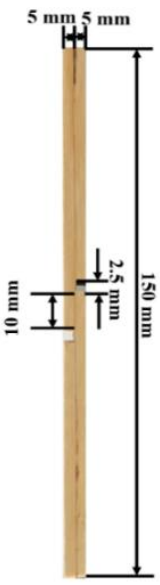

(b)

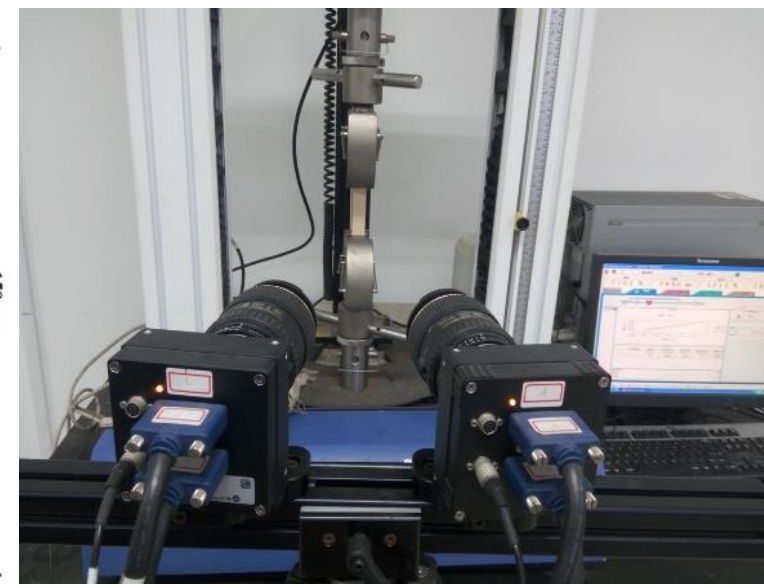

(c)

Fig. 2. Geometry and specification of the test specimens for the DIC and test scene: (a) the speckle pattern specimen of laminated bamboo lumber; (b) the specifications applied to the DIN EN standard 302-1 (2004) specimen; and (c) the specimen loaded with cameras

The surfaces of all the samples were polished with sandpaper. A random white and black spray pattern was spray-painted onto the surfaces of the test objects to ensure that the dot in the black and white matrix could be focused, in which the objective zone image could be collected by the 3D-DIC system (Fig. 2). Samples were clamped at both ends and stretched along the sample-length direction. To maintain stable conditions for the 3D-DIC measurement, a 50-N pre-load was applied to the samples before measurement. The samples were then strained in 10 steps of $50 \mathrm{~N}$ for each step, with loading speed of 2 $\mathrm{mm} / \mathrm{min}$, so the final load was $550 \mathrm{~N}$. The load was controlled in the elastic range. The micro-scale strain distribution of sample was collected by image and calculated. The data of the elastic modulus $(E)$ and Poisson's ratio $(\mu)$ in the fiber direction of the laminated bamboo lumber were obtained and were used as parameters in the following FEA evaluation.

\section{Parameter Settings for the Finite-element Analysis (FEA) Model}

The geometric model is shown in Fig. 3. It was assumed that the model was under tensile conditions. The movement of both ends of the sample was transversely restricted, and the only allowed movement was in the axial direction. A $550 \mathrm{~N}$ positive tensile load was loaded along the X-axis on the right-hand side of the model, and the gravity of the laminated bamboo lumber was neglected. 


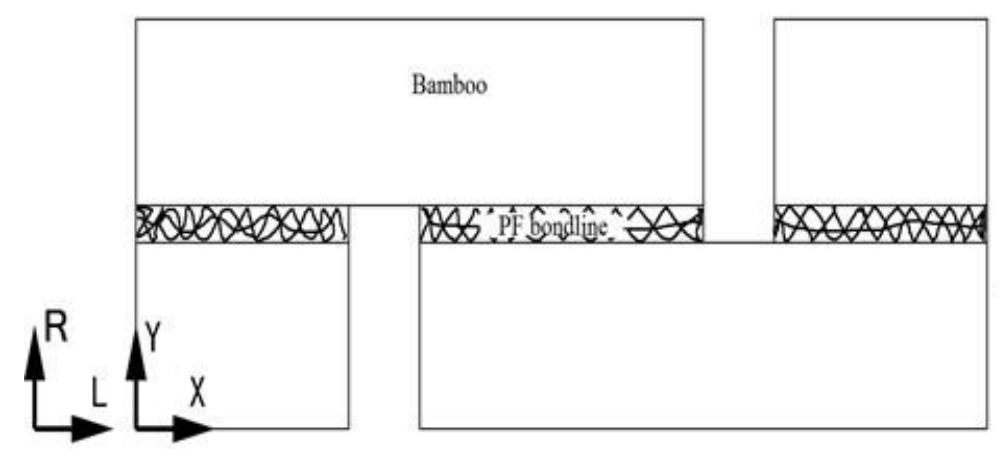

Fig. 3. Geometric model of the laminated bamboo lumber bondline

The elastic modulus, Poisson's ratio, and shear modulus of the bamboo were selected based on the above tested parameters of the bamboo strips. The size of the geometric model was confirmed based on experiments, with a bamboo size of $5 \mathrm{~mm}$ and a total model length of $30 \mathrm{~mm}$. The input data of the bond line thickness used for the model was calculated based on the bondline thickness from the SEM experimental investigation results, and the average bond line thickness was selected in the model.

\section{Finite-element Analysis (FEA) Simulation Process}

The upper and lower layers of the model were set as bamboo and the middle layer as adhesive. The properties of the bamboo and adhesive will be given in a following section.

The geometrical model was set up and then meshed into a finite number of units. Given that meshing could influence the calculation accuracy, the meshing quantity, density, and quality were taken into account (Guan et al. 2016). The model geometry was meshed with refinements in the bonding interface with mesh of $0.1 \mathrm{~mm} \times 0.35 \mathrm{~mm}$, where strain and stress concentrations were expected (Fig. 4). At the left end of the model, the movements in the $\mathrm{X}$-axis direction and in the $\mathrm{Y}$-axis direction were restricted. A tensile load of $550 \mathrm{~N}$ was applied to the right end of the sample. All calculated analyses were conducted using ANSYS software (Version 10.0, Ansys, Inc., Canonsburg, PA). The FEA simulation results were compared with the DIC experimental results, and the effectiveness and error of the FEA simulation was considered.

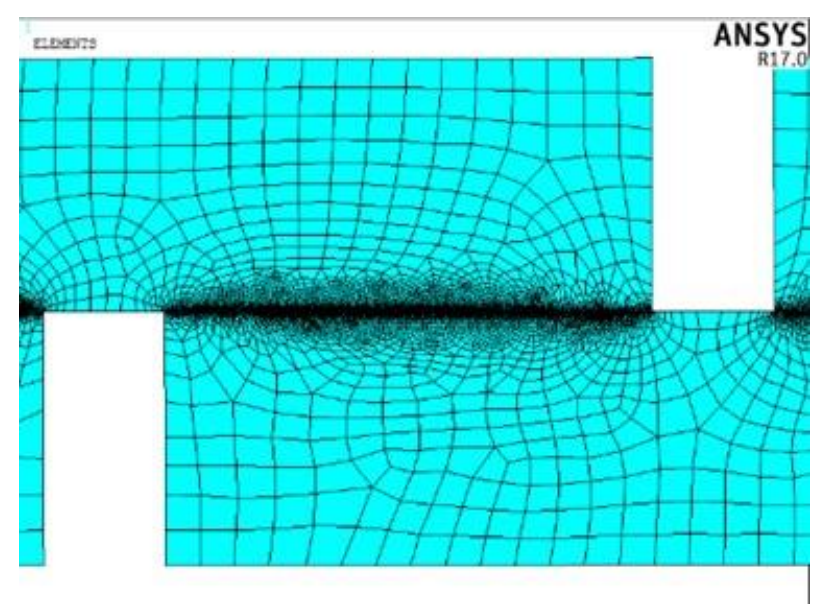

Fig. 4. FEA meshing at the bondline interface 


\section{Tensile Shear Strength of the Laminated Bamboo Lumber}

Four kinds of laminated bamboo lumber specimens were manufactured for tensile shear measurements according to DIN EN standard 302-1 (2004) and were fixed to the testing machine using pin-ended attachments. The specimen size was $150 \mathrm{~mm} \times 20 \mathrm{~mm} \times$ $10 \mathrm{~mm}$, and an overlap with a width of $10 \mathrm{~mm}$ was defined in the middle of the section center in the test pieces with thick glue lines. There were 10 replicates.

\section{RESULTS AND DISCUSSION}

\section{Parameters of the Bamboo Strips for Finite-element Analysis (FEA)}

The parameters of the bamboo strips used for the FEA simulation are shown in Table 1.

Table 1. Basic Parameters for the Finite-element Analysis (FEA) Model of the Laminated Bamboo Lumber

\begin{tabular}{|c|c|c|c|c|c|c|c|c|c|c|}
\hline Unit & Treatment & $\begin{array}{c}E_{\mathrm{L}} \\
(\mathrm{GPa})\end{array}$ & $\begin{array}{c}E_{\mathrm{R}} \\
(\mathrm{GPa})\end{array}$ & $\begin{array}{c}E_{\mathrm{T}} \\
(\mathrm{GPa})\end{array}$ & $\mu_{\mathrm{LR}}$ & $\mu_{\mathrm{LT}}$ & $\mu_{\mathrm{RT}}$ & $\begin{array}{c}\mathrm{G}_{\mathrm{LR}} \\
(\mathrm{GPa})\end{array}$ & $\begin{array}{c}\mathrm{GLT}_{\mathrm{LT}} \\
(\mathrm{GPa})\end{array}$ & $\begin{array}{c}G_{\mathrm{RT}} \\
(\mathrm{GPa})\end{array}$ \\
\hline $\begin{array}{c}\text { Bleached } \\
\text { bamboo } \\
\text { strip } \\
\text { ultrasonic } \\
\text { treatment }\end{array}$ & 11.14 & 0.602 & 0.602 & 0.217 & 0.217 & 0.135 & 0.602 & 0.602 & 0.14 \\
\hline $\begin{array}{c}\text { After } \\
\text { ultrasonic } \\
\text { treatment }\end{array}$ & 8.03 & 0.434 & 0.434 & 0.207 & 0.207 & 0.129 & 0.434 & 0.434 & 0.101 \\
\hline $\begin{array}{c}\text { Before } \\
\text { Carbonized } \\
\text { bamboo } \\
\text { strip }\end{array}$ & $\begin{array}{c}\text { ultrasonic } \\
\text { treatment }\end{array}$ & 9.86 & 0.533 & 0.533 & 0.24 & 0.24 & 0.15 & 0.533 & 0.533 & 0.124 \\
$\begin{array}{c}\text { After } \\
\text { ultrasonic } \\
\text { treatment }\end{array}$ & 6.59 & 0.356 & 0.356 & 0.201 & 0.201 & 0.126 & 0.356 & 0.356 & 0.083 \\
\hline
\end{tabular}

\section{Scanning Electron Microscopy (SEM) Morphology and Bond Line Thickness}

Images of the laminated bamboo lumbers and the morphology of the bonding interface of the laminated lumber bamboos are shown in Figs. 5 and 6. In addition, the bondline thickness results are displayed in Table 2, as well as the bonding line values, which were used for the FEA evaluation. As shown in Table 2, the increment of bondline thickness of LBBLU was more than 1.80 times that of LBBL, and the increment of bondline thickness of LCBLU was more than 1.23 times that of LCBL. Therefore, ultrasonic treatment on bamboo strip can distinctly increase the bondline thickness of laminated bamboo lumber.

Figure 5 shows the presence of an intact bondline in the cross-sections of the laminated bamboo lumber. Since bamboo does not have transverse tissue, e.g., wood rays, the pit of the cell wall is the only way for adhesive to penetrate. Therefore, it is difficult for adhesives to penetrate a bamboo block, and is distributed on the bamboo surface, especially between the cell walls and in the broken cell cavities formed during sample preparation. As a result, the thickness of the bond line is relatively small and straight. However, after ultrasonic treatment, the bond line was relatively larger and curved. More adhesive was able to penetrate the bamboo matrix since the pits in cell wall had been partly broken up under ultrasonic treatment. 

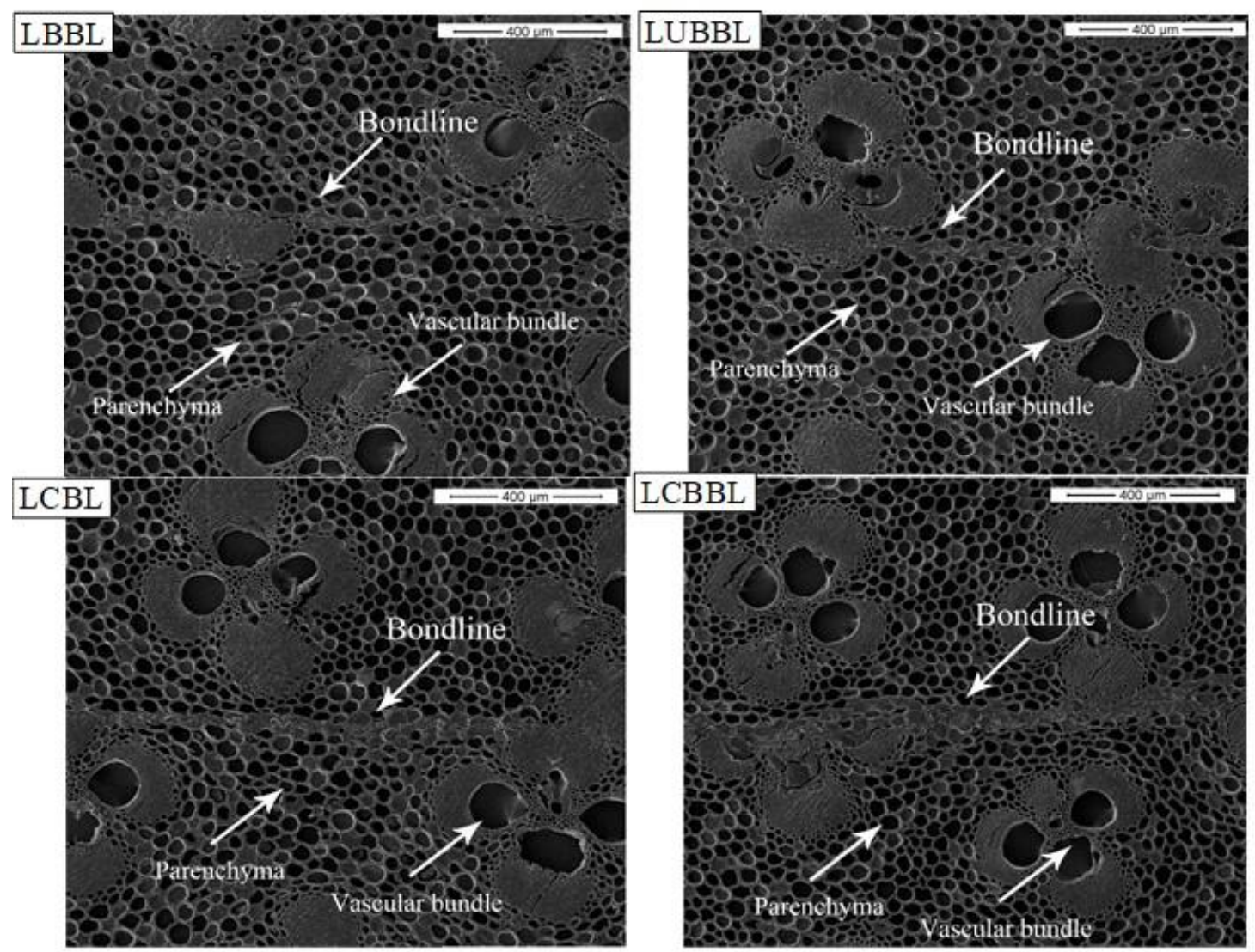

Fig. 5. SEM images of the LBBL, LUBBL, LCBL, and LUCBL samples

Figure 6 shows the presence of the bonding interface in the parenchyma area in the cross-sections of the laminated bamboo lumber. After the ultrasonic treatment, the boundary between the adhesive and the treated bamboo was not clear, and the deformation of the parenchyma cells near the bonding interface was more pronounced than the deformation in the untreated bamboo. The increased penetration of the adhesive enhanced the mechanical interlocking of the interface between the adhesive and bamboo, which led to an increase in the shear strength of the laminated bamboo lumber (Guan et al. 2016). As a result, the adhesive not only was distributed in the broken cell cavities on the surface during the phenolic resin preparation, but it also penetrated the farther parenchyma cells through an extended pit channel, leading to the increase in the bond line thickness (Table 2). The bondline value from the SEM measurement was used for the FEA model. 

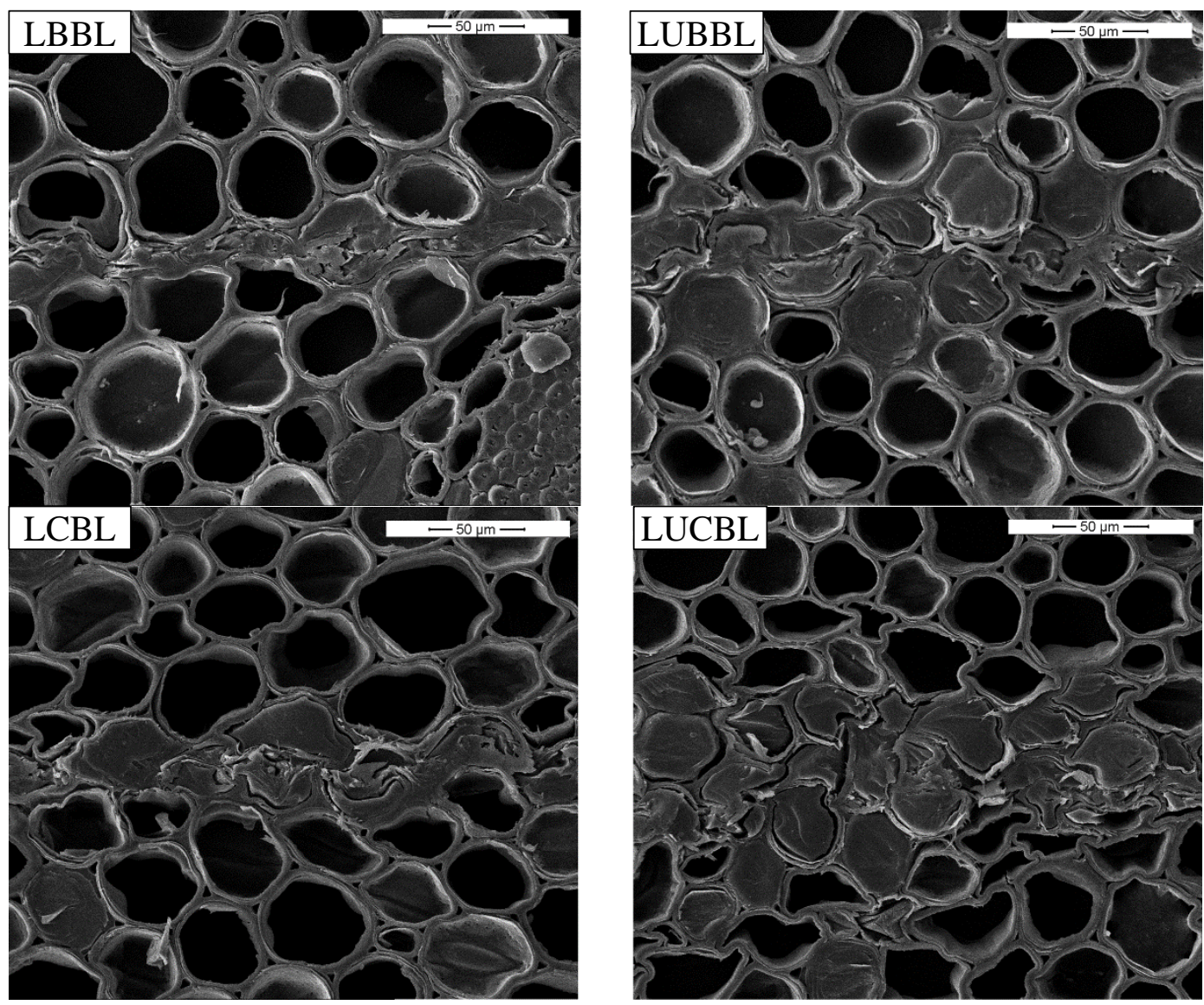

Fig. 6. Bonding interface morphology of the LBBL, LUBBL, LCBL, and LUCBL samples

Table 2. Bondline Thicknesses for the Finite-element Analysis (FEA) Model

\begin{tabular}{|c|c|c|c|}
\hline Sample & $\begin{array}{c}\text { Average Value of the } \\
\text { Bondline Thickness }(\mu \mathrm{m})\end{array}$ & $\begin{array}{c}\text { Standard Deviation } \\
(\mu \mathrm{m})\end{array}$ & $\begin{array}{c}\text { Variable } \\
\text { Coefficient }(\%)\end{array}$ \\
\hline LBBL & 22.7 & 2.13 & 9.38 \\
\hline LUBBL & 63.5 & 4.76 & 7.50 \\
\hline LCBL & 33.6 & 3.82 & 11.36 \\
\hline LUCBL & 74.8 & 5.38 & 7.19 \\
\hline
\end{tabular}

\section{Strain Distribution of the Bonding Interface via Digital Image Correlation (DIC)}

The DIC test results showed the strain distribution of the bonding interface of four kinds of laminated bamboo lumbers at $550 \mathrm{~N}$ (Figs. 7 and 8). Thus, the specimens at a 550 $\mathrm{N}$ tensile load were used for investigating the differences in strain distribution. The positive and negative strain value meant tensile and compressive strain, respectively. 

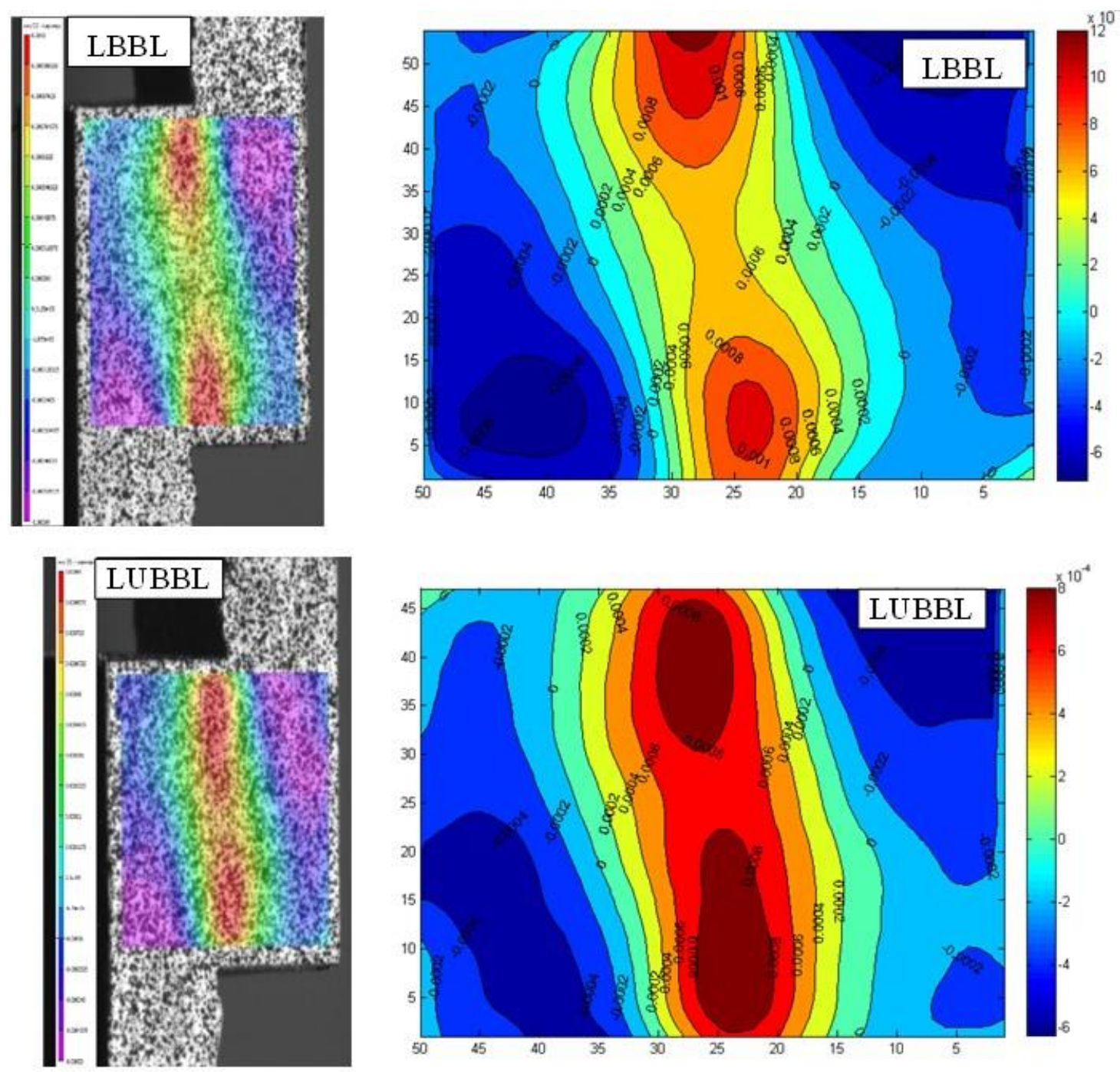

Fig. 7. Strain distribution of the LBBL and LUBBL samples (left is the strain area and right is the calculated value)

As shown in Fig. 7, the DIC measurements showed that the strain area (within the green surrounded area) of the LBBL and LUBBL samples almost covered half of the thickness of the sample; the thickness of the calculated strain zone was 4.0 to $4.5 \mathrm{~mm}$. The higher strain occurred at the ends of the overlapping area with a small volume. In the bonding interface region of the LBBL, the strain was $-6 \times 10^{-4}$ to $1 \times 10^{-3}$, while the data changed to $-4 \times 10^{-4}$ to $0.8 \times 10^{-3}$ in the LUBBL samples. Generally, the absolute value of the compressive strain and tensile strain of the LUBBL sample decreased. The lower the interface strain, the higher the interface strength, which demonstrated that the ultrasonic treatment could increase the shear strength of the laminated bamboo lumber. In addition, it showed that the higher shear strength not only relied on the higher mechanical interlock due to the greater adhesive penetration but also on the lower interface stress.

As shown in Fig. 8, the ultrasonic treatment did not cause much change in the strain distribution area across the bamboo bonding interface, coinciding with the previous study by Guan et al. (2016), in which the penetration depth of the adhesive into the bamboo surface was found to be relatively small. 

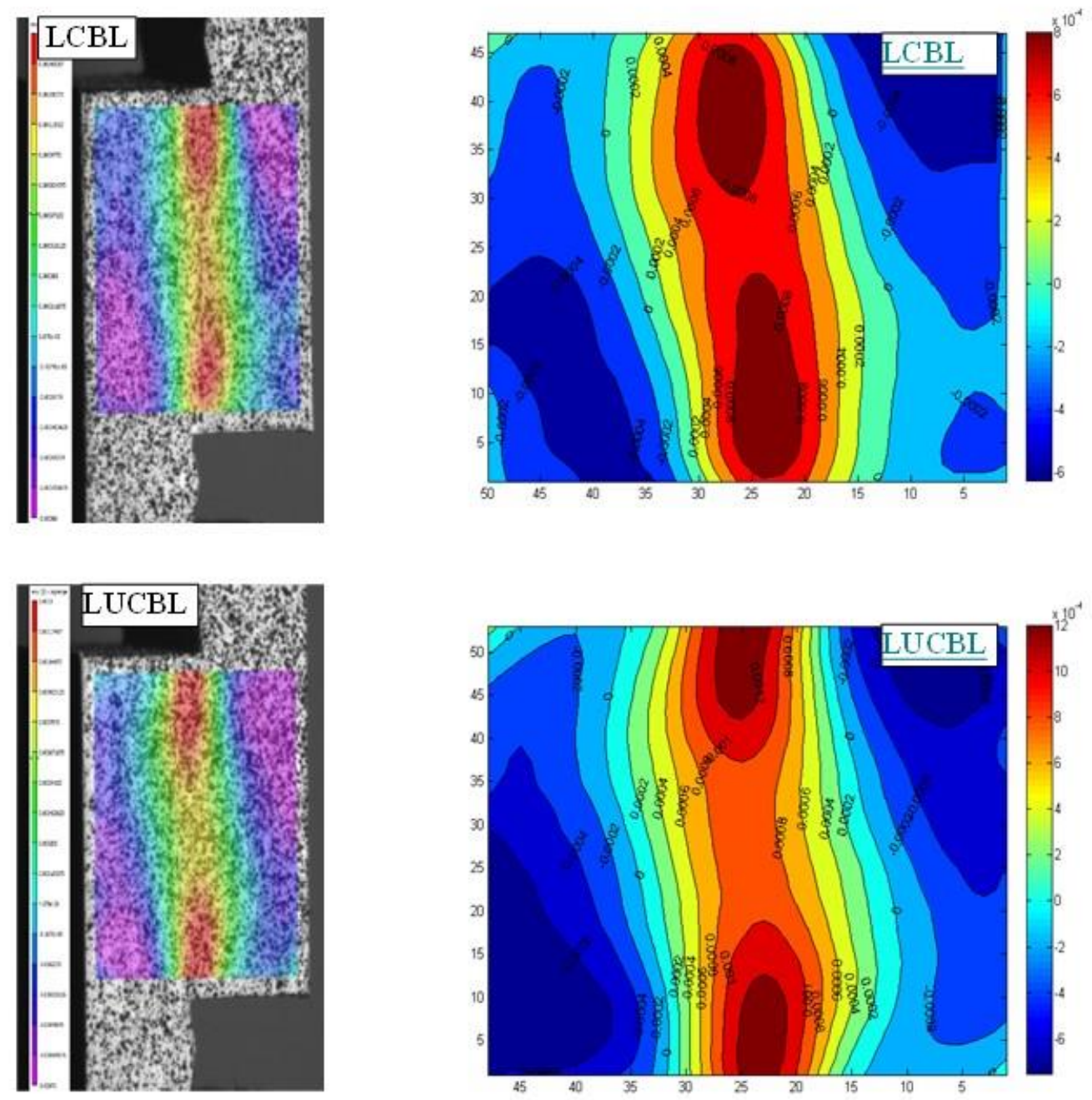

Fig. 8. Strain distribution of the LCBL and LUCBL samples (left is the strain area and right is the calculated value)

A previous study showed that adhesives could penetrate the cell wall, forming mechanical interlock and increasing the elastic modulus. The higher the elastic modulus of a material, the lower the interface strain (Guan et al. 2016). In addition, an ultrasonic treatment on bamboo strips increased the adhesive penetration depth in the bamboo bonding interface. This may increase the elastic modulus of the bamboo matrix near the bonding interface with the PF resin and accordingly decrease the strain value. However, the ultrasonic treatment could decrease the density of the bamboo matrix, which may decrease the elastic modulus of bamboo and increase the strain value. As a result, the strain value in the interface only slightly decreased.

Figure 8 also shows that a higher strain occurred at the ends of the overlapping area with small volume (Fig. 7). The strain zone width was slightly higher than the strain zone width of the LBBL and LUBBL samples, with the value of 4.5 to $4.8 \mathrm{~mm}$. This meant the effect of the ultrasonic treatment on the bleached bamboo strip and carbonized strips was different. The bonding interface region of the LCBL sample suffered a strain from $-5 \times 10^{-4}$ to $1.5 \times 10^{-3}$, while the strain changed from $-4.6 \times 10^{-4}$ to $1.2 \times 10^{-3}$ for the LUCBL sample. The mechanism was the same as that of the LCBL and LUCBL samples, as mentioned above. The lower the strain in the bonding interface, the higher the strength of the interface. 
A considerably higher shear strain concentration and a higher shear stress were observed in the bonding interface in the LCBL sample compared with the LBBL sample. This was because the shear strain distribution could be affected by the difference in the intensity between the bleached and carbonized bamboo strips. After the bleaching treatment, the elastic modulus increased with the density of the bamboo strips. After the carbonization treatment, the density and the cellulose and hemicellulose content decreased; therefore, the elastic modulus decreased, which may lead to a higher strain value in the bonding interface. This is one of the reasons that the shear strain of the LCBL sample was higher than the shear strain of LBBL the (Guan et al. 2016).

\section{Finite-element Analysis (FEA) Simulation of the Laminated Bamboo Lumber}

As shown in Figs. 9 and 10, the FEA simulation results showed that the shear strain distributions of the LBBL and LUBBL samples were similar and symmetrical on both sides. The stress and shear strain at the right end and lower part were higher than the stress and shear strain at the left end and upper part, respectively, because of the application of a positive tensile load to the right end and the load transmission from the right end to the left end. The FEA stimulations also showed that a higher strain appeared close to or at the ends of the overlapping areas with a small volume, which presented the same phenomenon as the DIC measurement. Therefore, this area was the center of the stress at which the bonding failure always occurred; the same phenomenon as found during the shear strength test. With the same load, if the strain value in the adhesive was too small to release stress, it might lead to more severe stress concentration. Thus, the higher the elastic modulus of the adhesive, the lower the strain value at the bonding interface. As a result, affected by a greater stress concentration, the strain area would be closer to the bonding interface between the bamboo and the adhesive, and the failure site would change from inside the adhesive to the weak layer of the bamboo matrix ( $\mathrm{Xu}$ et al. 2004). The adhesive used in the laminated bamboo lumber samples was the same, so the shear strength of the laminated bamboo lumber depended on the matrix near the interface. After ultrasonic treatment, the penetration amount and penetration depth of the adhesive all increased, which may lead to a better infiltration of the interfacial strength, thereby increasing the shear strength. As shown in Figs. 9 and 10, it was also found that the shear strain were distributed in a narrow area along the bonding interface due to the narrow bond line thickness. The transverse width of the strain zone was approximately $2 \mathrm{~mm}$ in the FEA simulation, while it was greater than $4 \mathrm{~mm}$ in the DIC measurement. This might be because of the variation of the elastic modulus of the bamboo matrix near the bonding interface due to adhesive penetration, or because of the low precision of the random white and black spray pattern on the surface due to narrow bond line thickness. 

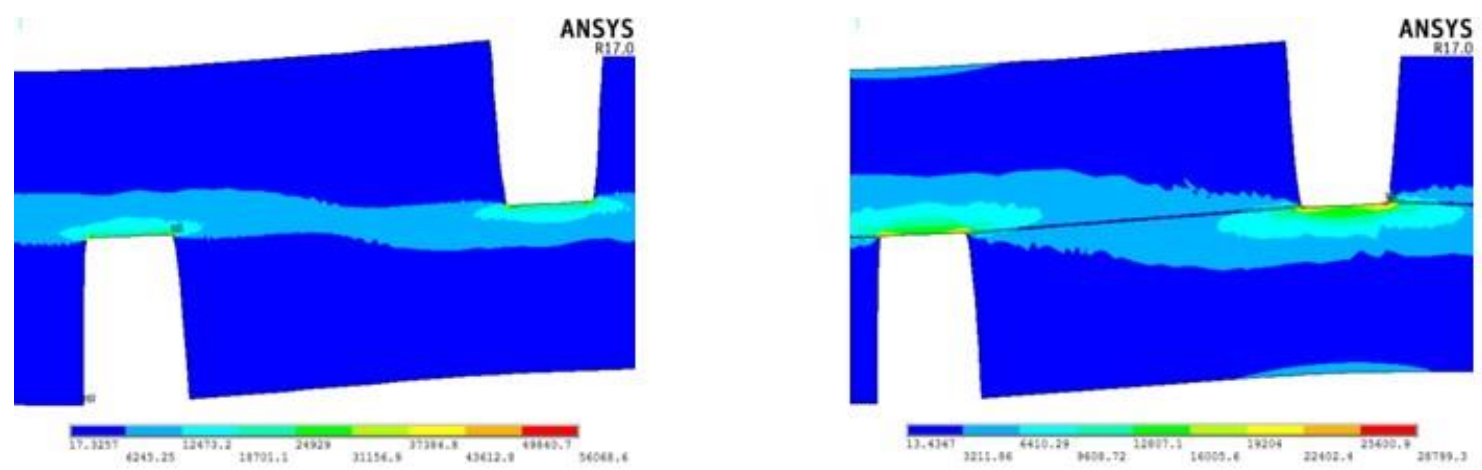

Fig. 9. Stress distribution of the LBBL sample (left) and the LUBBL sample (right)
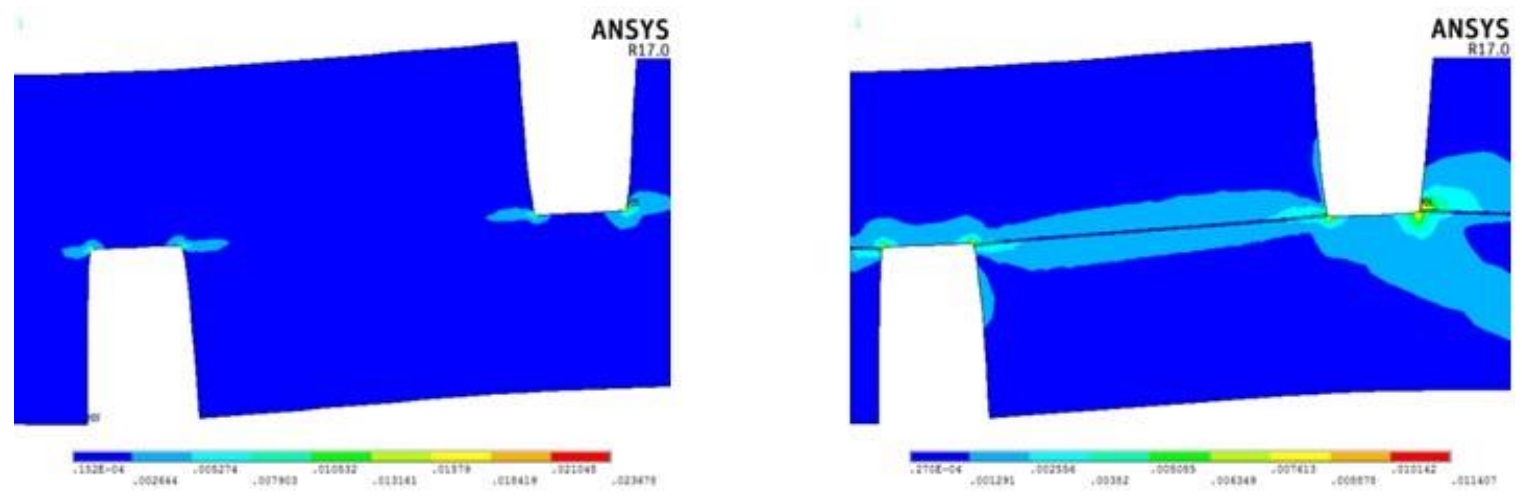

Fig. 10. Strain distribution of the LBBL sample (left) and the LUBBL sample (right)

However, a higher shear strain was observed in the FEA model than the shear strain measured via the DIC. The bamboo strips were compressed to some extent under hot pressure during manufacturing, so the density and elastic modulus increased. At the same time, adhesive penetrated into the bamboo cell walls during manufacturing, forming mechanical interlock, so the elastic modulus of the bamboo surface increased regardless of the small penetration depth. However, the real bond line was curved, the boundary between the bamboo and adhesive was not clear, and the elastic modulus along the bond line was not identical (Guan et al. 2016). In contrast, in the FEA simulations, to simplify the calculation, the bond line was set as a straight line, the boundary between the bamboo and adhesive was clear, and the elastic modulus was identical. As a result, an error occurred. Nevertheless, the FEA simulations presented more detailed information of the shear strain distribution along the bonding interface than the DIC measurements. In the DIC experiments, a random white and black spray pattern was made by hand on the surface, and the narrow bond line thickness resulted in small speckles sprayed in the bonding interface, causing insufficient precision. In the FEA simulations, the model geometry was meshed with refinements in the bonding interface (Fig. 4), which could show strain distribution in the bamboo bonding interface in more detail. At the same time, the FEA simulations could avoid random error sources, e.g., human error, ground vibration, and air movement. 

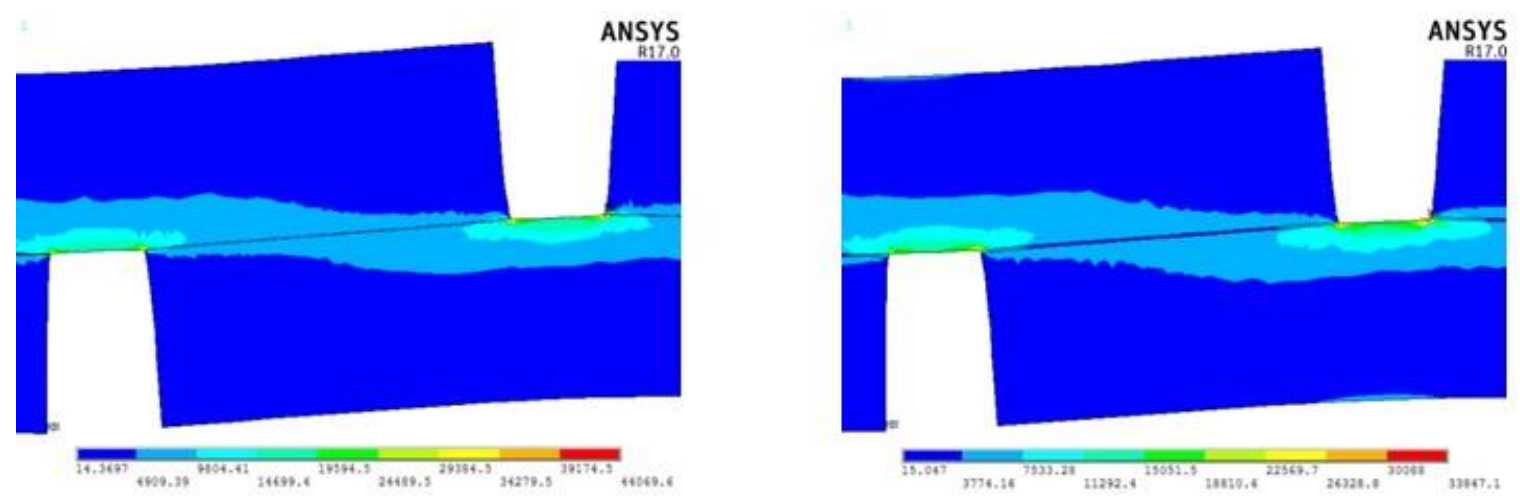

Fig. 11. Stress distribution of the LCBL sample (left) and the LUCBL sample (right)
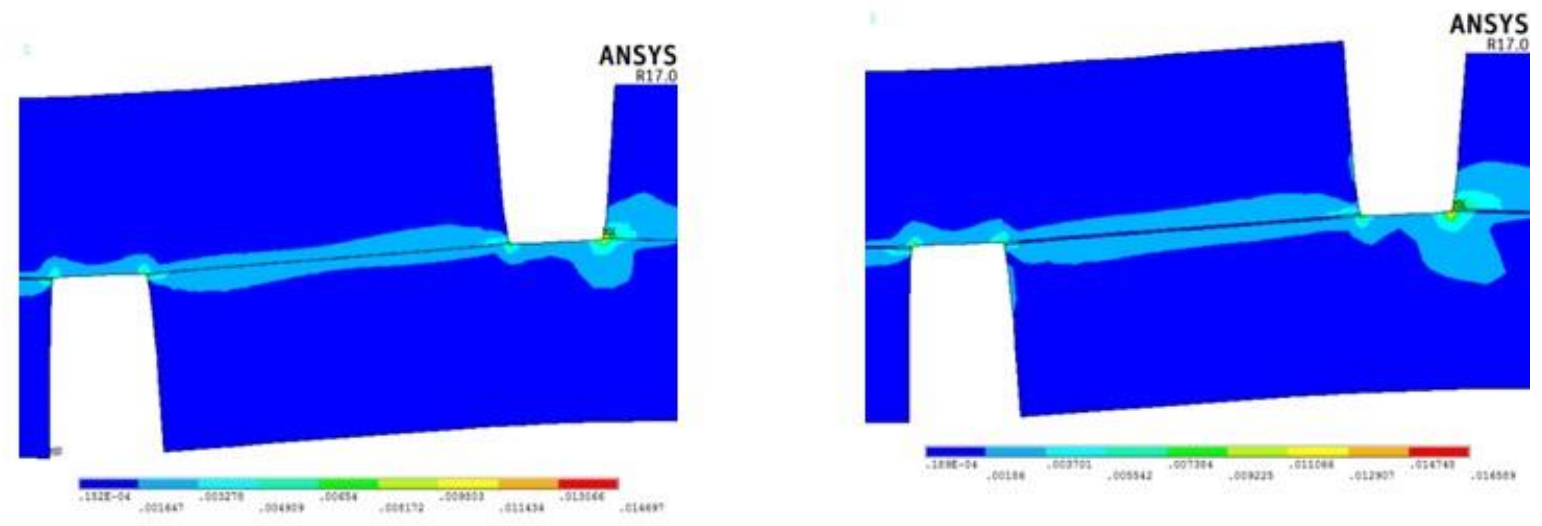

Fig. 12. Strain distribution of the LCBL sample (left) and the LUCBL sample (right)

According to the FEA simulation results shown in Figs. 11 and 12, the LCBL and LUCBL exhibited similar and symmetrical von Mises stress and shear strain distribution, respectively, on both sides before and after the ultrasonic treatment. The stress and shear strain at the right end and lower part of the LCBL and LUCBL samples were higher than the stress and shear strain of the LBBL and LUBBL samples, respectively. The center of stress also occurred at or was close to the ends of the overlapping area, as mentioned above, where the bonding failure always occurred.

After the carbonization treatment, the density of the bamboo strips and the content of cellulose and hemicellulose decreased, so the decreased elastic modulus resulted in a higher shear strain and a greater stress concentration (Guan et al. 2014).

\section{Shear Strength Testing and Failure Assessment}

Table 3 shows that the tensile strength of the laminated bamboo lumber increased after the bamboo strip underwent the ultrasound treatment. Loading displacement curves of each group are shown in Fig. 13. On the whole, the tensile strength of the LUBBL sample increased by greater than $20 \%$ compared to the LBBL sample, while the tensile strength of the LUCBL sample increased by approximately $15 \%$ compared to the LCBL sample. When the bamboo strips did not undergo the ultrasonic treatment, the LBBL sample showed better performance than the LCBL sample because of the difference in the matrix between the bleached and carbonized bamboo strips (Guan et al. 2016). Figure 14 shows that these 
results were consistent with the results of the DIC test and the FEA simulation test. As the thickness of the glue layer was increased by ultrasound, the tensile modulus of the glue interface increased, so more force was required to break it, and the location of the damage was farther from the location of the adhesive layer.

Table 3. Tensile Strength of Four Kinds of Laminated Bamboo Lumber

\begin{tabular}{|c|c|c|c|}
\hline Sample & $\begin{array}{c}\text { Average Value of Tensile } \\
\text { Strength (MPa) }\end{array}$ & $\begin{array}{c}\text { Standard Deviation } \\
(\mathrm{MPa})\end{array}$ & $\begin{array}{c}\text { Variable } \\
\text { Coefficient }(\%)\end{array}$ \\
\hline LBBL & 10.8 & 0.30 & 2.7 \\
\hline LUBBL & 13.2 & 0.27 & 2.0 \\
\hline LCBL & 10.0 & 0.25 & 2.5 \\
\hline LUCBL & 11.5 & 0.36 & 3.1 \\
\hline
\end{tabular}

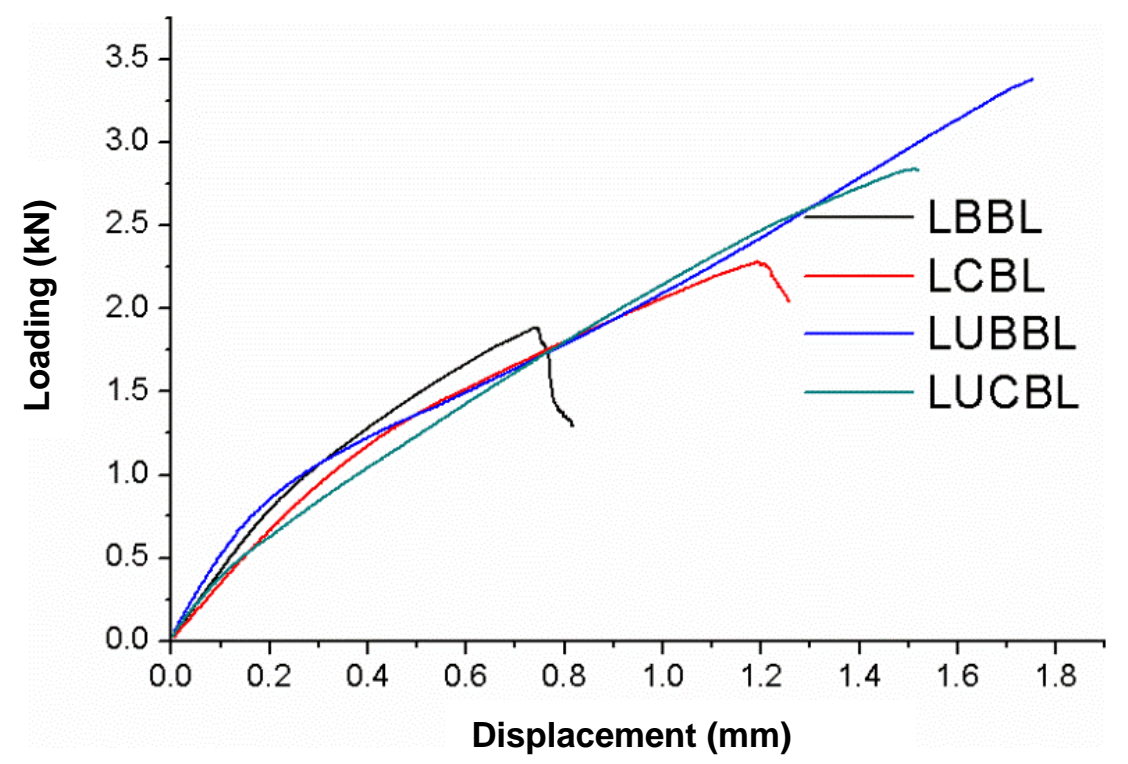

Fig. 13. Loading displacement curve of LBBL, LCBL, LUBBL and LUCBL
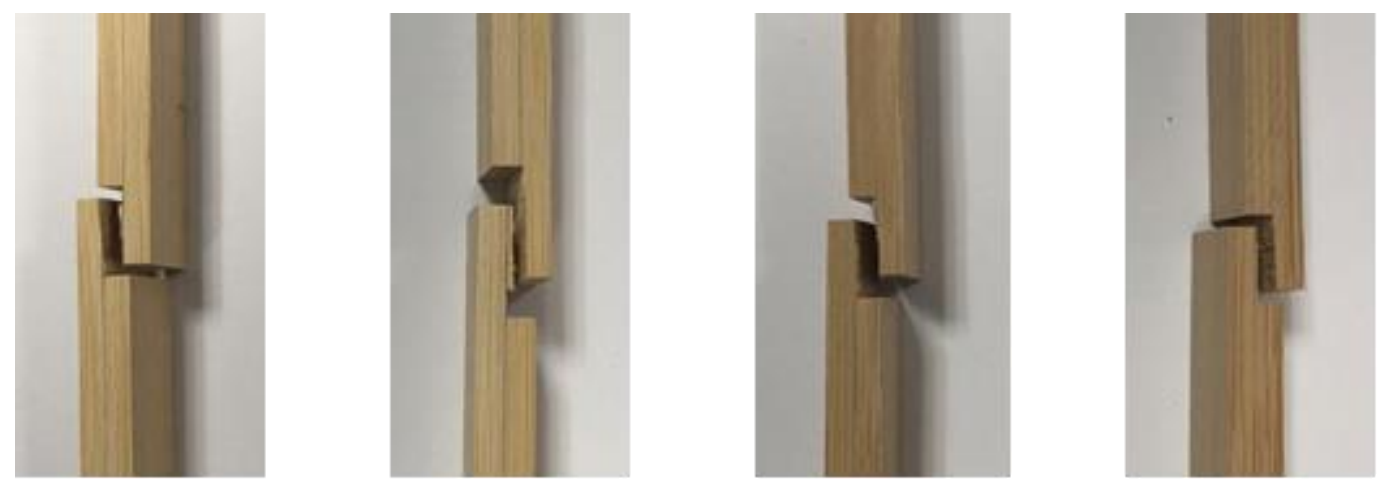

Fig. 14. Failure of the tensile testing of the LBBL, LUBBL, LCBL, and LUCBL 


\section{CONCLUSIONS}

1. The scanning electron microscope (SEM) images showed that the ultrasound treatment increased the penetration of the phenol-formaldehyde (PF) adhesive into the bamboo and enhanced the thickness of the bond line of the laminated bamboo lumber.

2. The digital image correlation (DIC) analysis results showed that the maximum strain and stress of the bonding interface decreased due to the increased PF adhesive penetration into the bamboo surface and the higher elastic modulus of the cell walls after the ultrasonic treatment on the bamboo bonding interface. Owing to the lower elastic modulus of the carbonized bamboo strips, a higher shear strain and greater stress concentration occurred at the carbonized bamboo bonding interface.

3. The finite element analysis (FEA) results appeared to agree with the DIC test results, showing that the shear strain distribution were similar and symmetrical on both sides. The stress and shear strain at the right end and lower part were higher than the stress and shear strain at the left end and upper part, respectively. The maximum stress and strain occurred close to or at the ends of the overlapping area; the same phenomenon found in the DIC measurements.

4. The DIC measurements and FEA simulations also illustrated that the shear strength of the laminated bleached bamboo lumber (LBBL) sample was higher than the shear strength of the laminated carbonized bamboo lumber (LCBL) sample.

\section{ACKNOWLEGEMENTS}

The Jiangsu Agricultural Science and Technology Innovation Fund (Grant No. CX (19) 3036) is much appreciated.

\section{REFERENCES CITED}

Bakar, E. S., Nazip, M. N. M., Anokye, R., and Hua, L. S. (2019). "Comparison of three processing methods for laminated bamboo timber production," Journal of Forestry Research 30(1), 363-369. DOI: 10.1007/s11676-018-0629-2

Blanchet, P., Gendron, G., Cloutier, A., and Beauregard, R. (2005). "Numerical prediction of engineered wood flooring deformation," Wood and Fiber Science 37(3), 484-496.

Chow, A., Ramage, M. H., and Shah, D. U. (2019). "Optimising ply orientation in structural laminated bamboo," Construction and Building Materials 212, 541-548. DOI: 10.1016/j.conbuildmat.2019.04.025

Correal, J. F., and Ramirez, F. (2010). "Adhesive bond performance in glue line shear and bending for glued laminated guadua bamboo," Journal of Tropical Forest Science 22(4), 433-439

Darzi, S., Karampour, H., Gilbert, B. P., and Bailleres, H. (2018). "Numerical study on the flexural capacity of ultra-light composite timber sandwich panels," Composites Part B: Engineering 155, 212-214. DOI: 10.1016/j.compositesb.2018.08.022

DIN EN 302-1 (2004). "Adhesives for load-bearing timber structures - Test methods Part 
1: Determination of bond strength in longitudinal tensile shear," German Institute for Standardization, Berlin, Germany.

GB/T 15780 (1995). "Testing methods for physical and mechanical properties of bamboos," Standardization Administration of China, Beijing, China.

Gindl, W., and Muller, U. (2006). "Shear strain distribution in PRF and PUR bonded 3ply wood sheets by means of electronic laser speckle interferometry," Wood Science and Technology 40, 351-357. DOI: 10.1007/s00226-005-0051-8

Grigsby, W., and Thumm, A. (2004). "Visualisation of UF resin on MDF fiber by XPS imaging," Holz als Roh-und Werkstoff 62, 365-369. DOI:10.1007/s00107-004-0499-5

Guan, M. J., Huang, Z., and Zeng, D. (2016). "Shear strength and microscopic characterization of a bamboo bonding interface with phenol formaldehyde resins modified with larch thanaka and urea," BioResources 11(1), 492-502. DOI: 10.15376/biores.11.1.492-502

Guan, M., Wang, L., and Yong, C. (2014). "Digital image correlation measuring shear strain distribution on wood/adhesive interphase modified by sealants," BioResources 9(3), 5567-5576. DOI: 10.15376/biores.9.3.5567-5576

Guan, M., Yong, C., and Wang, L. (2014). "Microscopic characterization of modified phenol-formaldehyde resin penetration of bamboo surfaces and its effect on some properties of two-ply bamboo bonding interface," BioResources 9(2), 1953-1963. DOI: $10.15376 /$ biores.9.2.1953-1963

Guan, M., Zhou, M., and Yong, C. (2013). "Antimold effect of ultrasonic treatment on Chinese Moso bamboo," Forest Products Journal 63(7-8), 288-291. DOI: 10.13073/FPJ-D-13-00035

He, X., Gu, F., and Ball, A. (2012). "Recent development in finite element analysis of self-piercing riveted joints," International Journal of Advanced Manufacturing Technology 58, 643-649. DOI: 10.1007/s00170-011-3414-3

Jeong, G. Y., and Park, M. J. (2016). "Evaluate orthotropic properties of wood using digital image correlation," Construction and Building Materials 113, 864-869. DOI: 10.1016/j.conbuildmat.2016.03.129

Konnerth, J., Valla, A., Gindl, W., and Muller, U. (2006). "Measurement of strain distribution in timber finger joints," Wood Science and Technology 40, 631-636. DOI: 10.1007/s00226-006-0090-9

Li, H., Su, J., Zhang, Q., Deeks, A. J., and Hui, D. (2015). "Mechanical performance of laminated bamboo column under axal compression," Composites Part B: Engineering 79, 374-382. DOI: 10.1016/j.compositesb.2015.04.027

Li, H., Wu, G., Xiong, Z., Corbi, I., Corbi, O., Xiong, X., Zhang, H., and Qiu, Z. (2019). "Length and orientation direction effect on static bending properties of laminated Moso bamboo," European Journal of Wood and Wood Products 77(4), 547-557. DOI: $10.1007 / \mathrm{s} 00107-019-01419-6$

Li, H., Zhang, Q., Huang, D., and Deeks, A. J. (2013). "Compressive performance of laminated bamboo," Composites Part B: Engineering 54, 319-328. DOI: 10.1016/j.compositesb.2013.05.035

Li, H., Zhang, Q., Wu, G., Xiong, X., and Li, Y. (2010). “A review on development of laminated bamboo lumber," Journal of Forestry Engineering 1(6), 10-16.

Li, Z., Yang, G. S., Zhou, Q., Shan, B., and Xiao, Y. (2018). "Bending performance of glulam beams made with different processes," Advances in Structural Engineering 22(2), 535-546. DOI: 10.1177/1369433218794327

Liese, W. (1998). The Anatomy of Bamboo Culms, Brill Publishers, Leiden, Netherlands. 
Ma, H. X. (2009). Interface Gluability and its Affecting Factors of Bamboo/Poplar Composite, Ph.D. Dissertation, Chinese Academy of Forestry, Beijing, China.

Rusch, F., Trevisan, R., Hillig, É., and Mustefaga, E. C. (2019). "Physical-mechanical properties of laminated bamboo panels," Pesquisa Agropecuária Tropical 4, 1-8.

Sebera, V., Muszynski, L., Tippner, J., Noyel, M., Pisaneschi, T., and Sundberg, B. (2015). "FE analysis of CLT panel subjected to torsion and verified by DIC," Materials and Structures 48(1-2), 451-459. DOI: 10.1617/s11527-013-0195-1

Serrano, E., and Enquist, B. (2005). "Contact-free measurement and non-linear finite element analysis of strain distribution along wood adhesive bonds," Holzforchung 59(6), 641-646. DOI: 10.1515/HF.2005.103

Takeuchi, C. P., Estrada, M., Linero, D. L. (2018). "Experimental and numerical modeling of shear behavior of laminated Guadua bamboo for different fiber directions," Construction and Building Materials 177, 23-32. DOI: 10.1016/j.conbuildmat.2018.05.040

Wong, ED., Yang, P., Zhang, M. et al. Analysis of the effects of density profile on the bending properties of particleboard using finite element method (FEM). Holz als Roh- und Werkstoff 61, 66-72 (2003). https://doi.org/10.1007/s00107-002-03509Xiao, Y., Wu, Y., Li, J., and Yang, R. Z. (2017). “An experimental study on shear strength of glulam," Construction and Building Materials 150, 490-500. DOI: 10.1016/j.conbuildmat.2017.06.005

Xu, M., Yao, X., Wang, G., Meng, L., and Jin, J. (2004). "Experimental studies on bending failure mechanics of bamboo laminate," Journal of Experimental Mechanics 19(3), 347-352.

Article submitted: August 10, 2021; Peer review completed: September 11, 2021; Revised version received and accepted: October 15, 2021; Published: December 10, 2021.

DOI: $10.15376 /$ biores.17.1.890-907 